\title{
0100 EVALUATION OF SCHOOL SPORTS INJURY PROBLEM AT SCHOOL LEVEL AMONG CHILDREN OF DHAKA CITY: “DEVELOPMENT OF SPORT INJURY SURVEILLANCE SYSTEM AT LARGE URBAN ENVIRONMENT"
}

S M Idris Ali*, M Khatun, A K M Fazlur Rahman Correspondence: Sher-e-Bangla Medical College, Mohammodia Housing Society, Road No. 02. House No. 95, Mohammadpur, Dhaka-1207, Bangladesh

\subsection{6/ip.2010.029215.100}

Injury is an emerging public health problem in both developed and developing countries, including Bangladesh. A total of 5122 diseased patients were attended in the Health clinic out of which $586(11.4 \%)$ were injury related in 1-year time. On an average, 48 injury-related patients attended per month. Peak incidence of injury was found in the month of June, July and September. On injury category trauma and abrasion were found as frequent injuries. Among the injuries trauma amounting the highest incidence $64.5 \%$. The next common injury was abrasion/laceration (17.1\%). Injury trauma includes simple trauma, traumatic haematoma and fractures. The fractures were diagnosed from referral Hospital.

Sports injury has been found as a major cause of illness among the school children. So prevention of sports injuries should be included in ongoing school health programme. 